\title{
Wear-corrosion performance of Si-DLC coatings on Ti-6Al-4V substrate
}

\author{
Jung-Gu Kim, ${ }^{1}$ Kwang-Ryeol Lee, ${ }^{2}$ Seok-Jo Yang ${ }^{3}$ \\ ${ }^{1}$ Department of Advanced Materials Engineering, Sungkyunkwan University, 300 Chunchun-Dong, \\ Jangan-Gu, Suwon 440-746, Korea \\ ${ }^{2}$ Future Technology Research Division, Korea Institute of Science and Technology, Cheongryang, \\ Sungbuk-Gu, Seoul 130-650, Korea \\ ${ }^{3}$ Department of Mechatronics Engineering, Chungnam National University, 220 Gung-Dong, Yuseong-Gu, \\ Daejeon, 305-764, Korea
}

Received 3 November 2006; revised 2 May 2007; accepted 16 May 2007

Published online 16 October 2007 in Wiley InterScience (www.interscience.wiley.com). DOI: 10.1002/jbm.a.31632

\begin{abstract}
Si-incorporated diamond-like carbon (Si-DLC) coatings ranging from 0 to 2 at \% Si were deposited on Tialloy substrate by means of radio frequency plasmaassisted chemical vapor deposition (r.f. PACVD) technique, using a mixture of benzene $\left(\mathrm{C}_{6} \mathrm{H}_{6}\right)$ and silane $\left(\mathrm{SiH}_{4}\right)$ as the reaction gas. The synergy in wear and corrosion of Si-DLC coatings was investigated by tribological and electrochemical techniques. The electrolyte used in this test to simulate the corrosive environment of body fluid was a 0.89 wt $\% \mathrm{NaCl}$ solution of $\mathrm{pH} 7.4$ at $37^{\circ} \mathrm{C}$. This study provides quantitative data for the assessment
\end{abstract}

of the effect of Si incorporation on the synergistic effect between wear and corrosion in the simulated body fluid environment. In conclusion, tribological and electrochemical measurements showed that the Si-DLC films could improve wear-corrosion resistance in the simulated body fluid environment owing to the lower friction coefficient, corrosion rate, delamination area, and water uptake. (c) 2007 Wiley Periodicals, Inc. J Biomed Mater Res 86A: 41-47, 2008

Key words: wear; corrosion; DLC; biomaterial; Ti

\section{INTRODUCTION}

Wear and corrosion are defined as the electrochemical and mechanical interaction leading to degradation of biomaterials in rolling and sliding in the simulated corrosive environment of the body fluid. The synergy between wear and corrosion increases the overall degradation rate of biomaterials. Moreover, wear and corrosion are the most destructive processes for biomaterial surfaces, and, in synergy, they cause severe problems by decreasing the lifetime of biomaterials. Many authors have investigated the possible synergistic effects in wear and corrosion. ${ }^{1-6}$ Methods for measuring wear-corrosion synergy and penetration rate equations to quantify the wear and corrosion have been produced. ${ }^{7}$

Recently, many researchers have focused on the development of protective coatings to improve the wear

Correspondence to: J.-G. Kim; e-mail: kimjg@skku.ac.kr

Contract grant sponsor: Center for Nanostructured Materials Technology (21st Century Frontier R\&D Programs of the Ministry of Science and Technology, Korea); contract grant number: 06K1501-01610

(C) 2007 Wiley Periodicals, Inc. and corrosion problem of biomaterials to increase their lifetime. As one possible solution, diamond-like carbon (DLC) coatings have been extensively studied recently due to their unique combination of properties. Si-incorporated DLC (Si-DLC) coatings have attracted special research interest due to their potential to improve several properties of pure DLC coatings such as hardness, friction coefficient, wear and corrosion resistance, and biocompatibility. ${ }^{8}$ This remarkable collection of properties has led many researchers to investigate the potential of Si-DLC coatings as a protective coating for biomaterials. The wear and corrosion resistance of Si-DLC coatings on STS 316L were improved with increasing Si content owing to high $\mathrm{sp}^{3}$ bonding, that is, $\mathrm{Si}$ addition has the beneficial effect of promoting surface nucleation. ${ }^{9}$ The Si impurity may increase nucleation rate by $80-$ fold and the growth rate by threefold. ${ }^{10}$ The incorporation of $\mathrm{Si}$ in the DLC films improved their corrosion resistance due to the formation of a thick silicon oxide layer on the Si-DLC film surfaces. ${ }^{11}$

The goal of this work is to experimentally evaluate the effect of Si-incorporation on the synergistic effect between wear and corrosion of DLC on Ti alloy. To characterize this synergistic effect appro- 
priately, it is necessary to measure the degradation parameters such as friction coefficients, corrosion rates, delamination area $\left(A_{\mathrm{d}}\right)$, and volume fraction of water uptake $(V)$ during wear testing and wearcorrosion testing by tribological and electrochemical techniques.

\section{EXPERIMENTAL}

\section{Sample preparation}

Ti alloy (Ti-6Al-4V) was used as a substrate material. Samples of 37-mm diameter Ti alloy were cut from a 2$\mathrm{mm}$ thick sheet. Si-DLC coatings were deposited on mirror-polished substrate. The sample surfaces were mechanically ground and polished using 2000-grit $\mathrm{SiC}$ and $0.3-\mu \mathrm{m}$ diamond paste for the final step. After sequential cleaning with TCE-acetone-methanol in ultrasonic cleaner, the polished samples were stored under vacuum. Details of the deposition equipment have been previously described elsewhere. ${ }^{12} \mathrm{~A}$ substrate was placed on the water-cooled cathode where $13.56 \mathrm{MHz}$ r.f. power was delivered through the impedance-matching network. In the r.f. PACVD method, the vacuum chamber is evacuated by a rotary pump and a turbo molecular pump to a base pressure of $\sim 2.0 \times 10^{-3}$ Pa prior to deposition. Before deposition, the substrates were precleaned using argon plasma for $15 \mathrm{~min}$ at a bias voltage of $-400 \mathrm{~V}$ and a pressure of $0.5 \mathrm{~Pa}$. The coatings were deposited at a bias voltage of $-400 \mathrm{~V}$ and a deposition pressure of $1.33 \mathrm{~Pa}$. The precursor gas for the Si-DLC coatings was a mixture of $\mathrm{C}_{6} \mathrm{H}_{6}$ and $\mathrm{SiH}_{4}$ for the Si-DLC coatings. The Si-DLC coatings were produced with three different $\mathrm{Si}$ contents $(0$ at \% as control, 1.0 at \%, and 2.0 at \%). An amorphous 5-nm thick $\mathrm{Si}$ interlayer was deposited onto the substrate prior to the Si-DLC coatings to improve the adhesion between the coating and substrate. A total coating thickness of about $1 \mu \mathrm{m}$ was achieved in all cases. The coating thickness was analyzed by $\alpha$-step profilometer.

\section{Tribological tests}

Two types of ball-on-disk experiments were conducted in this study to simulate the corrosive environment of body fluid, which consists of $0.89 \% \mathrm{NaCl}$ of $\mathrm{pH} 7.4$ at $37^{\circ} \mathrm{C}$ : wear testing under ambient air and wear-corrosion testing in the electrolyte. The former was performed to provide a basic comparison with the latter conducted in an electrolyte. Figure 1 shows the schematic diagram of the setup used for the wear-corrosion test. The tests were carried out using a ball-on-disk type surface friction apparatus. The flat substrate was rotated against the ball (alumina counterpart, $4.5-\mathrm{mm}$ diameter). Alumina was chosen as the ball material because of its chemical inertness under various corrosive environments. A dead load of $2 \mathrm{~N}$ was applied. The sliding speed, sliding length, sliding distance, and sliding time were $0.05 \mathrm{~ms}^{-1}, 12 \mathrm{~mm}, 500 \mathrm{~m}$, and about $3 \mathrm{~h}$, respectively. During wear-corrosion tests, EIS measurements were conducted at an interval of $24 \mathrm{~h}$ under static conditions.

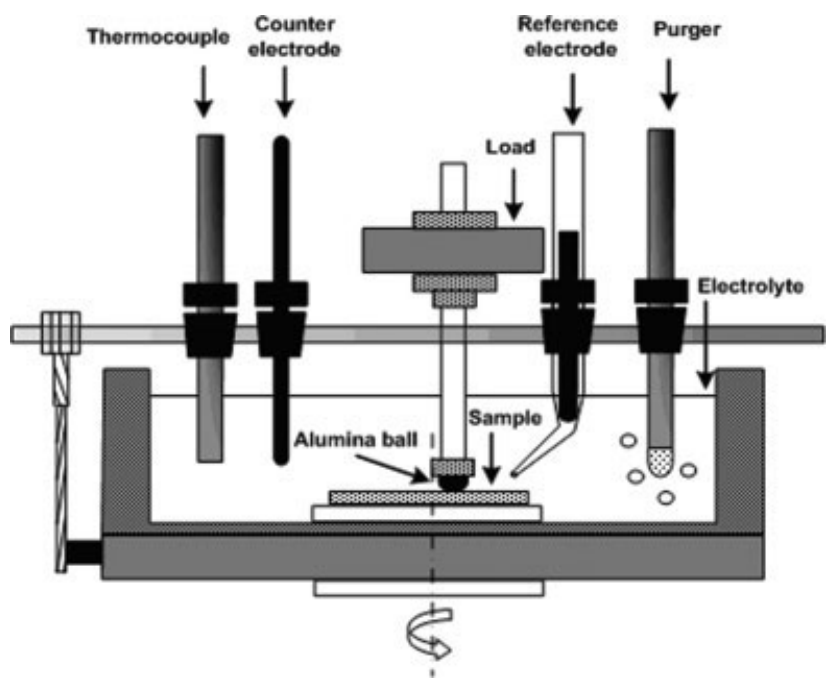

Figure 1. Schematic diagram of the equipment used for wear-corrosion experiments.

\section{Electrochemical tests}

EIS measurements were taken in a $0.89 \% \mathrm{NaCl}$ solution of $\mathrm{pH} 7.4$ at $37^{\circ} \mathrm{C}$, which was thoroughly deaerated by bubbling high purity nitrogen gas for $0.5 \mathrm{~h}$ prior to specimen immersion and continuously purged during the test. Saturated calomel electrode (SCE) and pure graphite were used as the reference and counter electrodes, respectively. An IM6e system was employed to measure the electrochemical impedance. The impedance measurements were performed using a frequency range of $10 \mathrm{kHz}$ to $10 \mathrm{MHz}$. The peak-to-peak amplitude of the ac signal was $10 \mathrm{mV}$. The impedance data were analyzed by the IM6e analysis software (THALES) program, which uses a nonlinear least square fitting.

EIS was used to determine the corrosion rate, delamination area, and water uptake of coatings exposed to an electrolyte. The corrosion rate is obtained through the following equation ${ }^{13,14}$ :

$$
i_{\text {corr }}=\frac{\beta_{\text {ox }, \mathrm{M}} \times \beta_{\text {red,C }}}{2.3 \times R_{\mathrm{p}} \times\left(\beta_{\mathrm{ox}, \mathrm{M}}+\beta_{\mathrm{red}, \mathrm{C}}\right)}
$$

where $i_{\text {corr }}=I_{\text {corr }} / A$ in $\mu \mathrm{A} / \mathrm{m}^{2}, \beta_{\text {ox }, \mathrm{M}}$ is the anodic Tafel constant in $\mathrm{mV} /$ decade $\left(100 \mathrm{mV} /\right.$ decade), $\beta_{\text {red, } C}$ the cathodic Tafel constant in $\mathrm{mV} /$ decade $\left(100 \mathrm{mV} /\right.$ decade), $R_{\mathrm{p}}$ the polarization resistance in $\mathrm{k} \Omega \mathrm{cm}^{2}$, and $A$ the area.

$$
\text { Corrosion Rate }(\mathrm{mpy})=\frac{0.13 \times i_{\text {corr }}\left(\mu \mathrm{A} / \mathrm{cm}^{2}\right) \times \mathrm{EW}}{\operatorname{density}\left(\mathrm{g} / \mathrm{cm}^{3}\right)}
$$

where 0.13 is the metric and time conversion factor and EW the equivalent weight in grams.

The extent of $A_{\mathrm{d}}$ and $V$ was determined from the experimental values of pore resistance $\left(R_{\text {pore }}\right)$ and coating capacitance $\left(C_{\text {coat }}\right)$ obtained by the impedance diagrams on the basis of the equivalent circuit. ${ }^{15}$

$$
A_{\mathrm{d}}=\frac{R_{\text {pore }}^{\mathrm{o}}}{R_{\text {pore }}}
$$


(a)

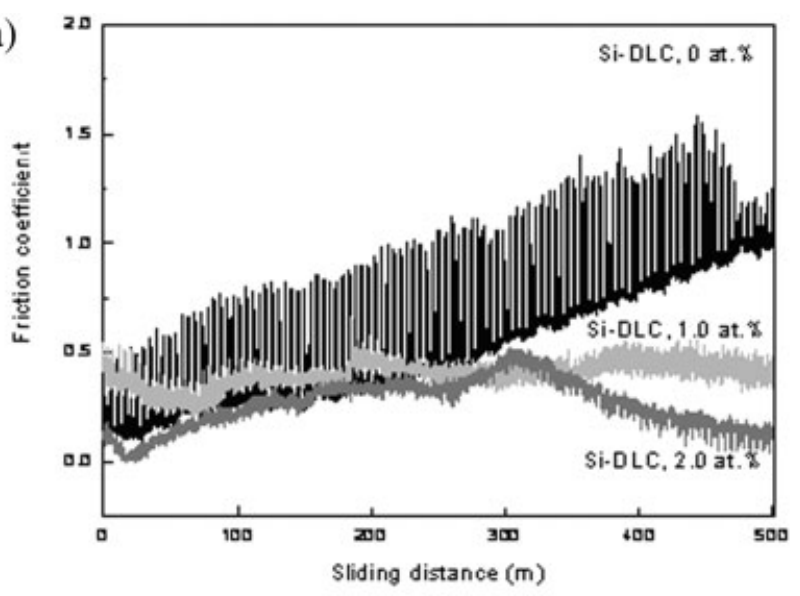

(b)

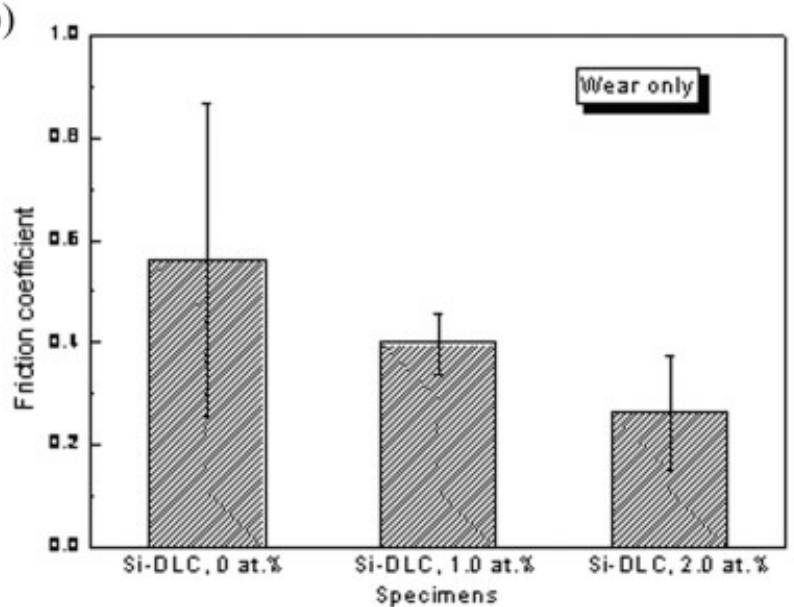

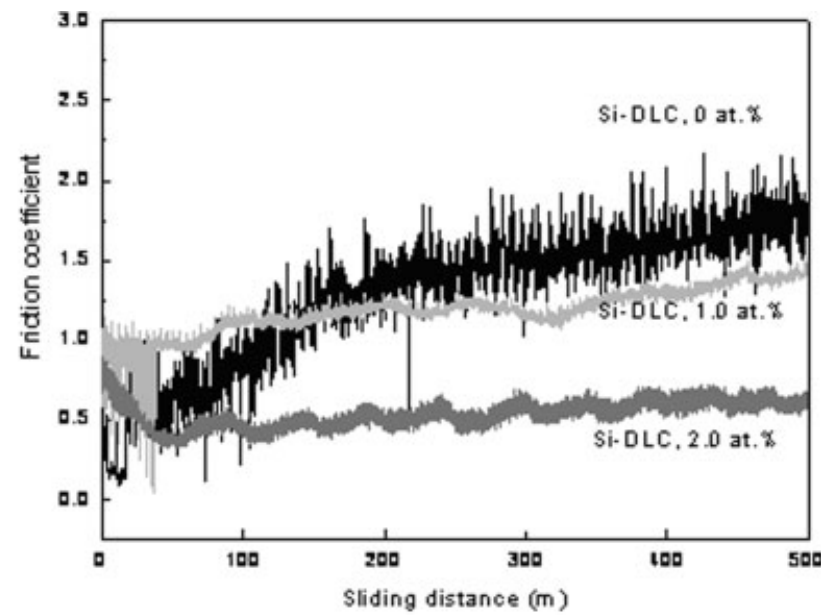

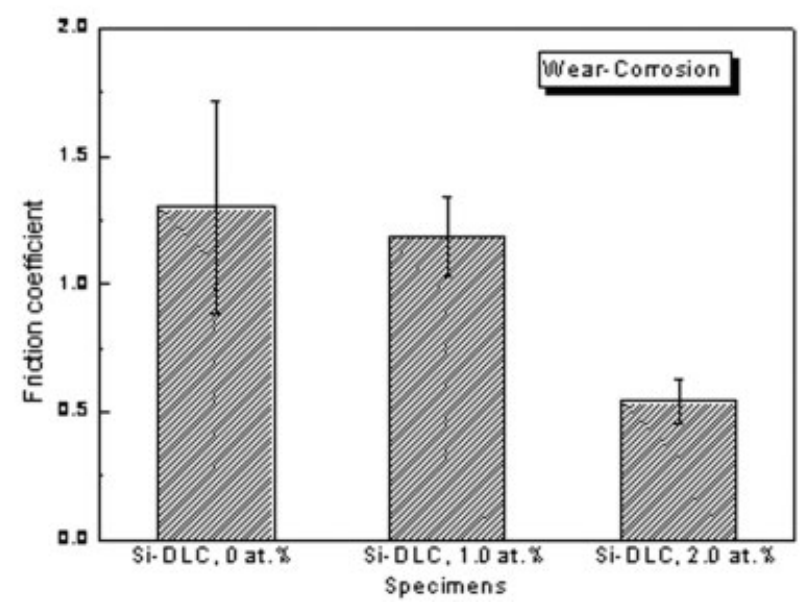

Figure 2. Comparison of friction coefficients for the coatings. (a) Under wear-only and (b) under wear-corrosion condition.

$$
\begin{gathered}
R_{\text {pore }}^{\mathrm{o}}=\rho \times d\left(\mathrm{ohm} \mathrm{cm}^{2}\right) \\
V=\frac{\log \left(C_{\text {coat }}(t) / C_{\text {coat }}(0)\right)}{\log 80}
\end{gathered}
$$

where $R_{\text {pore }}^{\mathrm{o}}$ is the characteristic value for the corrosion reaction at the solution/coating interface, $d$ the coating thickness, $\rho$ the coating resistivity, $C_{\text {coat }}(t)$ the coating capacitance as a function of time $(t)$, and $C_{\text {coat }}(0)$ the initial coating capacitance obtained from EIS data at initial exposure time.

\section{Surface analysis}

Scanning electron microscopy (SEM) at a voltage of 20 $\mathrm{keV}$ was used to examine the surface morphology of the coatings and the corroded surfaces of the tested specimens.

\section{RESULTS AND DISCUSSION}

\section{Tribological properties}

To gain a better understanding of wear degradation, an evaluation of the friction coefficient is worthwhile. The results presented in Figure 2(a,b) support a relationship between the friction coefficient and sliding distance of the Si-DLC coatings under wear-only and wear-corrosion conditions in the simulated body fluid environment. The average friction coefficients of the Si-DLC coatings were $0.2630,0.3989$, and 0.5617 under wear-only condition and $0.5407,1.1826$, and 1.2997 under wear-corrosion condition for $\mathrm{Si}$ content of 2.0, 1.0, and 0 at \%, respectively.

Furthermore, while the friction coefficients of the Si-DLC coatings $(2.0$ at $\%$ and 1.0 at $\% \mathrm{Si}$ ) under both wear-only and wear-corrosion conditions indicated a slight increase or a constant variation that of the DLC coating ( 0 at \% $\mathrm{Si})$ showed a continuous increase. For the 2 at \% Si-DLC coating under wearonly condition, the friction coefficients continuously increased with the increasing sliding distance up to $300 \mathrm{~m}$, after which it continuously decreased. The friction coefficients under wear-corrosion condition were considered to be higher than those under wear-only condition because the synergistic effect between wear and corrosion accelerates material 


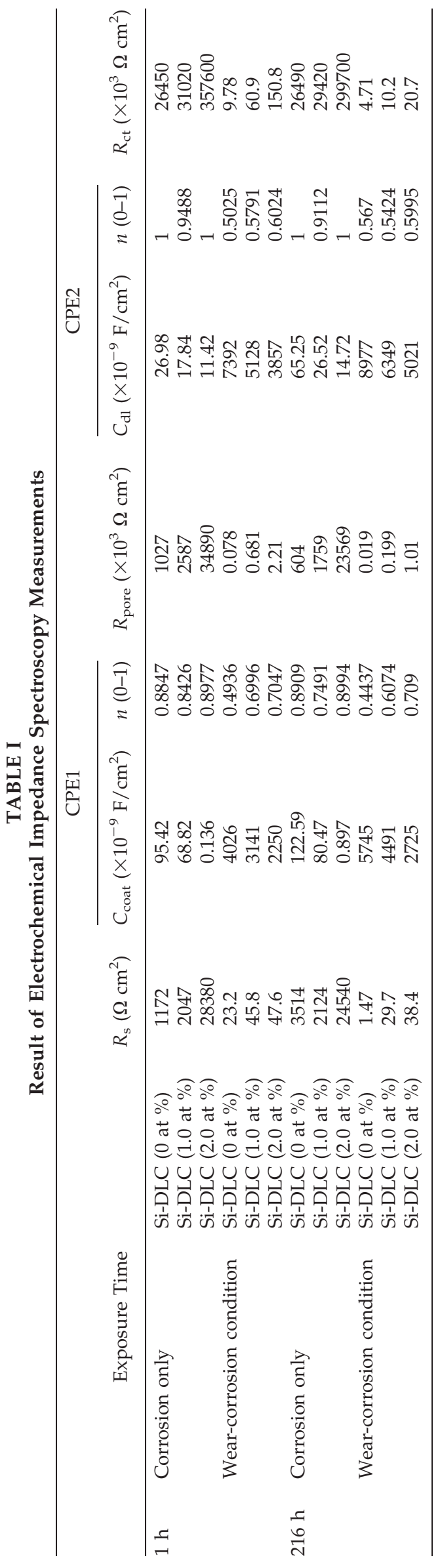

degradation by blistering and penetrating of water and ions between the coating and substrate. The friction coefficient was highly sensitive to surface films, possibly due to the breakdown of the passive film and an associated increase in surface roughness. The continuous abrasion caused considerable wear debris and accumulation of corrosion products in the wear track, which further retarded repassivation. The friction coefficients of the Si-DLC coatings decreased with the increasing Si content.

\section{Electrochemical properties}

The charge transfer resistance $\left(R_{\mathrm{ct}}\right)$ of the coating/ substrate interface under both corrosion-only and wear-corrosion conditions decreased gradually with the increasing immersion time, as shown in Table I, due to the degradation of the coating, which protects the metal against the gradual penetration of water and ions. There is some deviation of the data at several low frequency points. Constant phase elements (CPEs) are used in better data fitting to allow for depressed semicircles. $C_{\text {coat }}$ and $C_{\mathrm{dl}}$ are replaced with CPE1 and CPE2, respectively. This can also be described in terms of a distribution of relaxation times. $^{16}$

$$
Z_{\mathrm{CPE}}=Z_{\mathrm{o}}(j \omega)^{-n}
$$

where $Z_{\mathrm{o}}$ is the adjustable parameter used in the nonlinear least squares fitting, $\omega$ is angular frequency, and the factor $n$, defined as a CPE power, is an adjustable parameter that always lies between 0.5 and 1 .

The $R_{\mathrm{ct}}$ values of the Si-DLC coatings under wearcorrosion condition were much lower than those of the Si-DLC coatings under corrosion-only condition, as the synergistic effect between wear and corrosion accelerated material degradation by eliminating corrosion products or passive films.

TABLE II

Corrosion Rates (mpy) of Si-DLC-Coated Ti Alloy by EIS Method

\begin{tabular}{|c|c|c|c|}
\hline Exposur & Time & & $\begin{array}{l}\text { Corrosion } \\
\text { Rate (mpy) }\end{array}$ \\
\hline \multirow[t]{6}{*}{$1 \mathrm{~h}$} & \multirow[t]{3}{*}{ Corrosion-only } & Si-DLC (0 at \%) & 0.51 \\
\hline & & Si-DLC (1.0 at \%) & 0.44 \\
\hline & & Si-DLC (2.0 at \%) & 0.04 \\
\hline & \multirow{3}{*}{$\begin{array}{l}\text { Wear-corrosion } \\
\text { condition }\end{array}$} & Si-DLC (0 at \%) & 1382.75 \\
\hline & & Si-DLC (1.0 at \%) & 222.15 \\
\hline & & Si-DLC (2.0 at \%) & 90.34 \\
\hline \multirow[t]{6}{*}{$216 \mathrm{~h}$} & \multirow[t]{3}{*}{ Corrosion-only } & Si-DLC (0 at \%) & 0.51 \\
\hline & & Si-DLC (1.0 at \%) & 0.46 \\
\hline & & Si-DLC (2.0 at \%) & 0.05 \\
\hline & \multirow{3}{*}{$\begin{array}{l}\text { Wear-corrosion } \\
\text { condition }\end{array}$} & Si-DLC (0 at \%) & 2883.19 \\
\hline & & Si-DLC (1.0 at \%) & 1355.09 \\
\hline & & Si-DLC $(2.0$ at $\%)$ & 654.64 \\
\hline
\end{tabular}




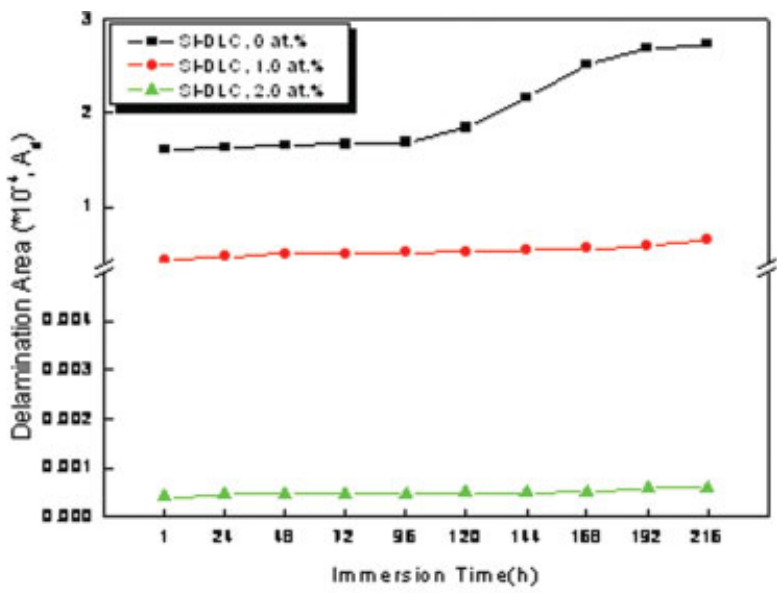

(a)

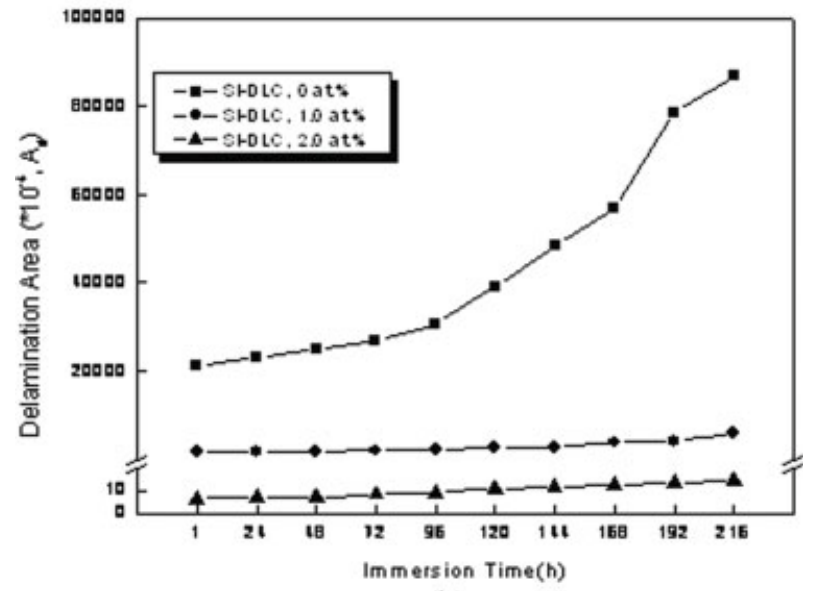

(b)

Figure 3. Delamination area as a function of immersion time. (a) Under corrosion-only and (b) under wear-corrosion conditions. [Color figure can be viewed in the online issue, which is available at www.interscience.wiley.com.]

The $R_{\mathrm{ct}}$ and $R_{\mathrm{p}}$ values of the substrate to corrosion were inversely related to corrosion rate of the substrate. The corrosion rates under both corrosion-only and wear-corrosion conditions as a function of immersion time are presented in Table II. With increasing immersion time, the rates under the former condition were not changed, whereas under the latter they were greatly accelerated. This contrasting result was because the continuous localized abrasion in the corrosive environment increased corrosion rates at the wear sites as a result of the formation of a galvanic cell between the wear track and unworn surface.

The $R_{\mathrm{ct}}$ values of the Si-DLC coatings $(2.0$ at \% and 1.0 at $\% \mathrm{Si}$ ) were higher than those of the DLC coating (0 at \% Si), suggesting that the Si-DLC coatings absorb less water and fewer ions with increasing Si content.

From the EIS measurements, $A_{\mathrm{d}}$ and $V$ of the SiDLC coatings continuously increased with the increasing immersion time under both corrosion-only and wear-corrosion conditions, as shown in Figures 3 and $4 . A_{\mathrm{d}}$ was affected by $V$ through porous coating because water penetration in the coating led to delamination and blisters. Increasing exposure time increased the volume fraction of water uptake. $A_{\mathrm{d}}$ and $V$ of the Si-DLC coatings under wear-corrosion condition were much higher than those under corrosion-only condition.

In addition, $A_{\mathrm{d}}$ and $V$ of the Si-DLC coatings with increasing Si content were lower than those of the DLC coating ( 0 at \% Si), as shown in Figures 3 and 4 . In other words, the DLC coating (0 at \% Si) tends to absorb more water due to the enhancement of diffusion mechanisms of active species through the coating.

\section{Surface analysis}

To further examine the wear and corrosion behaviors of the Si-DLC coatings, worn surface images of the wear tracks under both wear-only and wear-

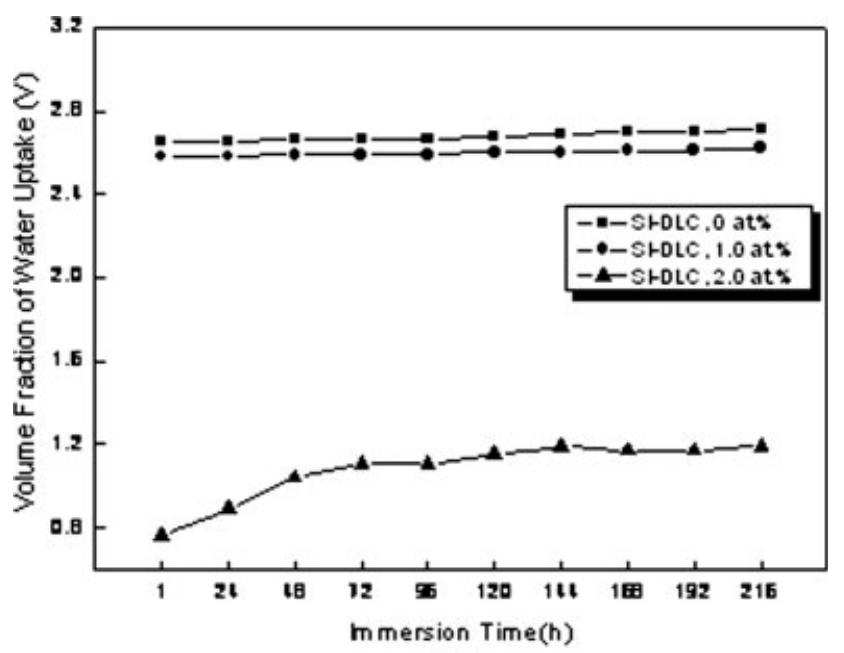

(a)

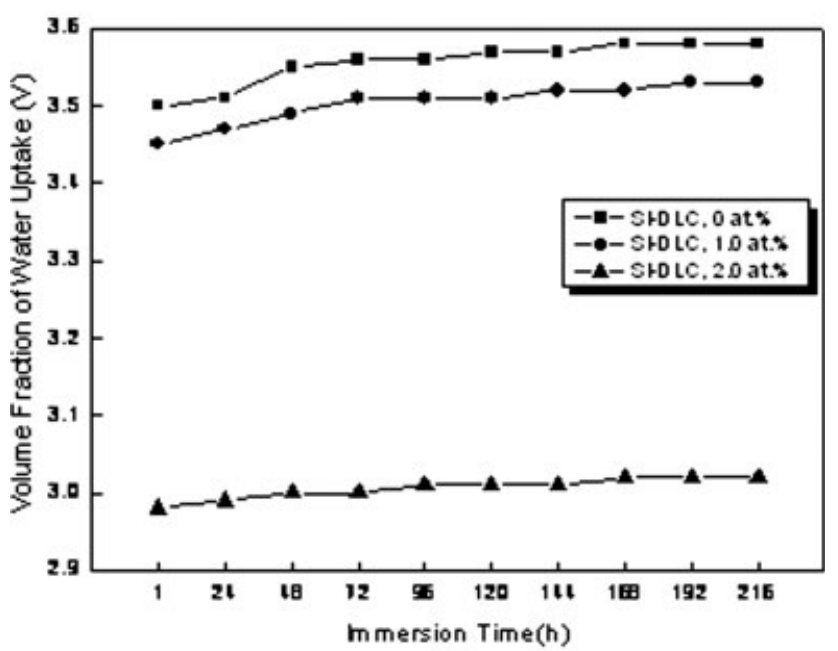

(b)

Figure 4. Volume fraction of water uptake as a function of immersion time. (a) Under corrosion-only and (b) under wear-corrosion conditions. 
(a)
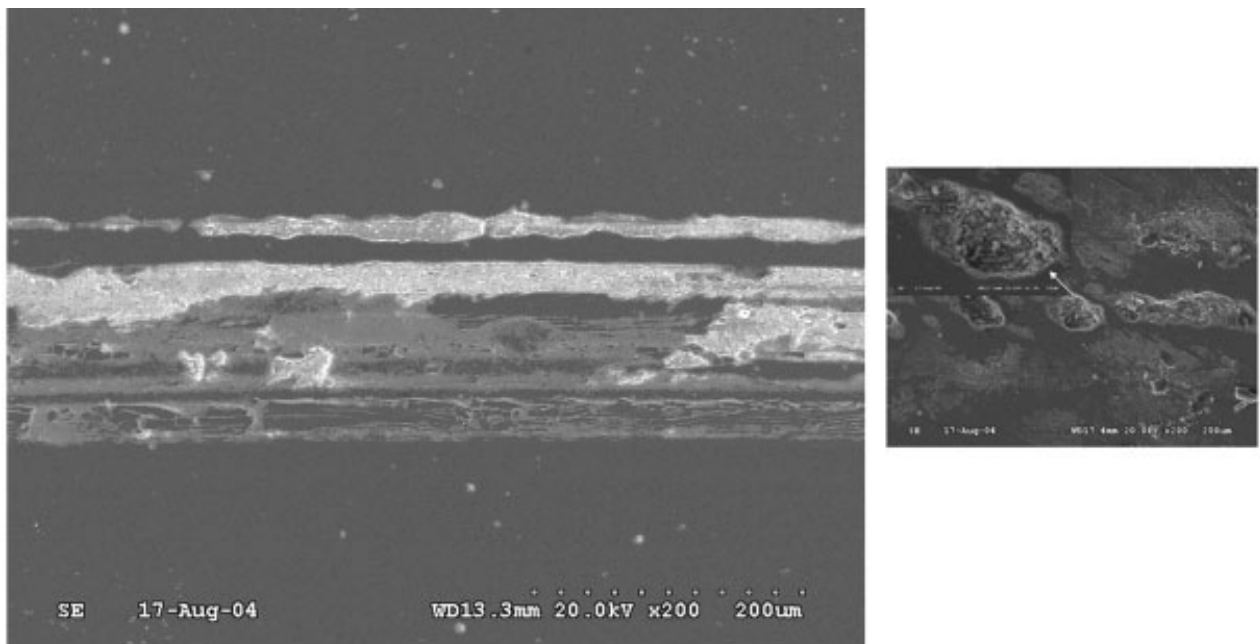

(b)

(c)
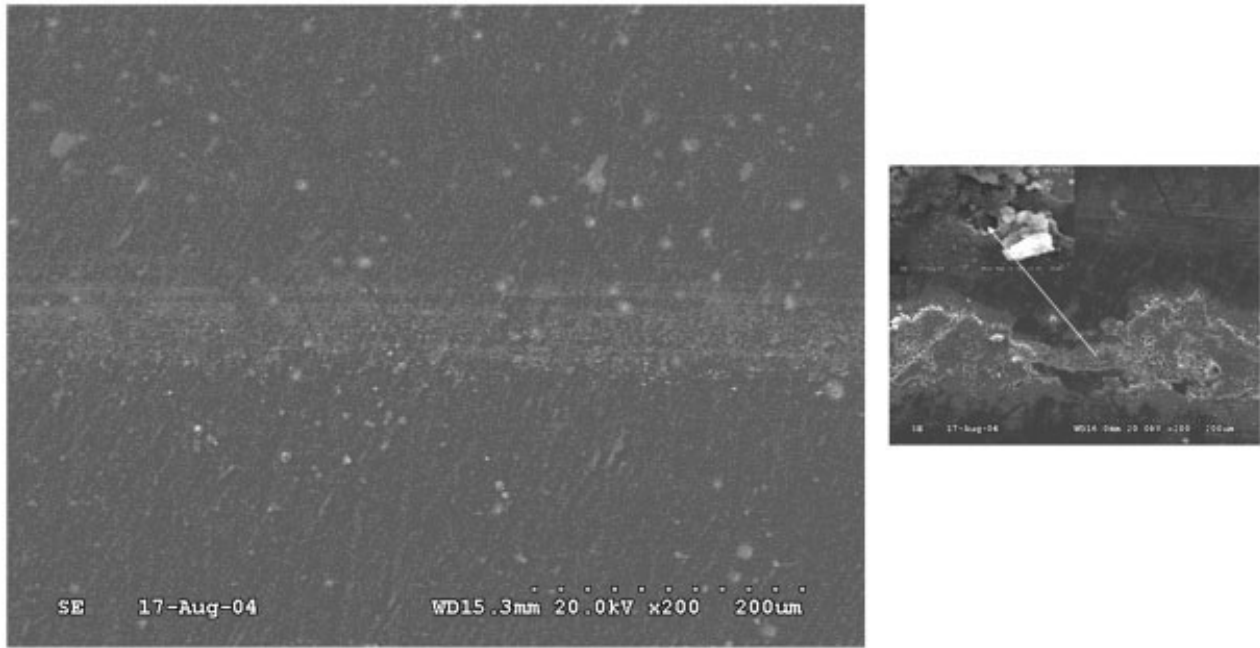

(d)

(e)
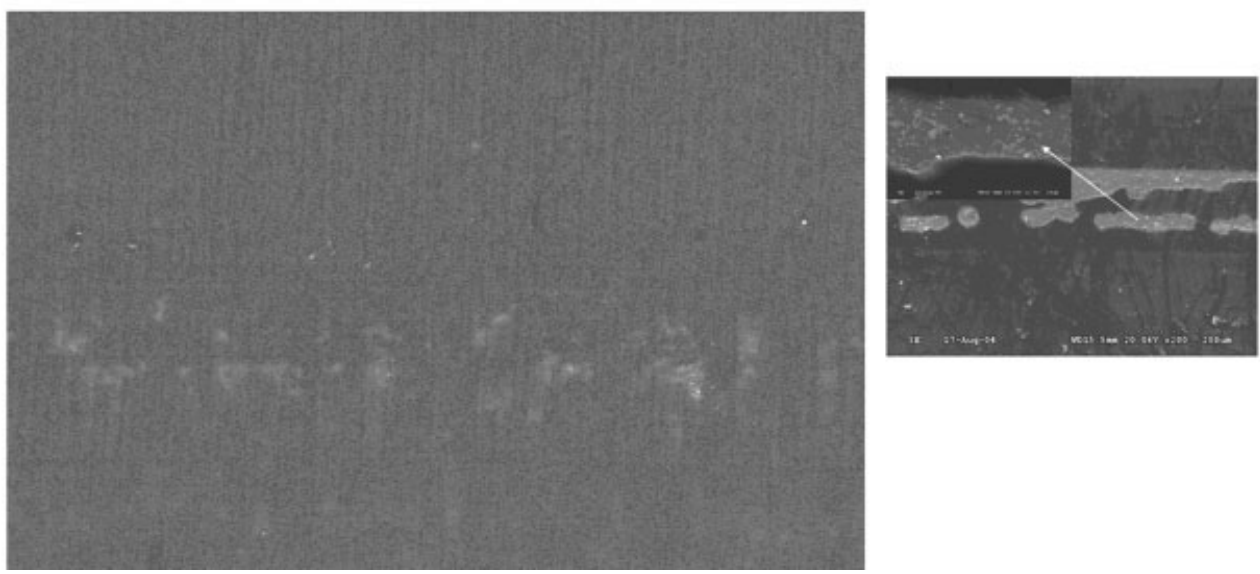

(f)

Figure 5. SEM images showing surface morphologies of Si-DLC coatings after wear and wear-corrosion tests. (a, d) DLC, 0 at \%, (b, e) Si-DLC, 1.0 at \%, (c, f) Si-DLC, 2.0 at \%, (a-c) wear test, and (d-f) wear-corrosion test.

corrosion conditions are depicted in Figure 5(a-f). The former revealed smoothly worn surfaces coupled with some evidence of ostensible surface deformation, whereas the latter indicated coating failure, blisters, and localized fracture. This was due to the removal of the passive film so that damaged coating caused blistering and fracture followed by the removal of coating fragments during wear-corrosion test. In addition, those blisters that were formed within the wear-corrosion track became fractured. Thus, this fractured coating surface can provide the direct diffusion paths for the corrosion medium and thereby enable localized corrosion and propagation of pitting. 
Especially, the worn surface of the DLC coating (0 at $\% \mathrm{Si}$ ) showed obvious signs of cracking and spalling within the edge of the wear-corrosion track, as shown in Figure 5. The worn surfaces of the Si-DLC coatings with the increasing Si content were much smoother in appearance and the coating remained intact, although scuffed and deformed, which conforms with the result of a lower friction coefficient and higher wear resistance. Moreover, the surface morphology of the Si-DLC coatings with the increasing $\mathrm{Si}$ content indicated a lower level of water and ion penetration, clearly indicating the excellent wearcorrosion resistance and absence of any significant damage.

\section{CONCLUSIONS}

Si-incorporated DLC coatings were deposited on Ti-6Al-4V alloy substrate by means of r.f. PACVD technique for improving the wear-corrosion properties. Increasing $\mathrm{Si}$ content reduced the friction coefficients, corrosion rates, delamination area, and volume fraction of water uptake in the Si-DLC coatings.

\section{References}

1. Güleryüz $\mathrm{H}$, Çimenoğlu $\mathrm{H}$. Effect of thermal oxidation on corrosion and corrosion-wear behavior of a Ti-6Al-4V alloy. Biomaterials 2004;25:3325-3333.

2. Madsen BW. Measurement of erosion-corrosion synergism with a slurry wear test apparatus. Wear 1988;123:127-142.

3. Zhou S, Stack MM, Newman RC. Characterization of synergistic effects between erosion and corrosion in an aqueous environment using electrochemical techniques. Corrosion 1996;52:934-946.
4. Eisenbarth E, Velten D, Schenk-Meuser K, Linez P, Biehl V, Duschner $\mathrm{H}$, Breme J, Hildebrand $\mathrm{H}$. Interactions between cells and titanium surfaces. Biomol Eng 2002;19:243-249.

5. Wan GJ, Huang N, Leng YX, Yang P, Chen JY, Wang J, Sun H. TiN and Ti-O/TiN films fabricated by PIII-D for enhancement of corrosion and wear resistance of Ti-6A1-4V. Surf Coat Technol 2004;186:136-140.

6. Liang H, Shi B, Fairchild A, Cale T. Applications of plasma coating in artificial joints: An overview. Vacuum 2004;73:317326.

7. Barril S, Mischler S, Landolt D. Triboelectrochemical investigation of the friction and wear behaviour of TiN coating in a neutral solution. Tribol Int 2001;34:599-608.

8. Damasceno JC, Camargo SS Jr, Freire FL Jr, Carius R. Deposition of Si-DLC films with high hardness, low stress and high deposition rates. Surf Coat Technol 2000;133:247-252.

9. Kim HG, Ahn SH, Kim JG, Park SJ, Lee KR. Effect of Siincorporation on wear-corrosion properties of diamond-like carbon films. Thin Solid Films 2005;482:299-304.

10. Liu H, Dandy DS. Diamond Chemical Vapor Deposition. New Jersey: Noyes Publications; 1995. p 44-60.

11. Choi J, Nakao S, Kim J, Ikeyama M, Kato T. Corrosion protection of DLC coatings on magnesium alloy. Diamond Relat Mater 2007;16:1361-1364.

12. Lee KR, Kim MG, Cho SJ, Eun KY, Seong TY. Structural dependence of mechanical properties of $\mathrm{Si}$ incorporated diamond-like carbon films deposited by RF plasma-assisted chemical vapour deposition. Thin Solid Films 1997;308:263267.

13. ASTM Standard G102-90. Standard Practice for Calculation of Corrosion Rates and Related Information from Electrochemical Measurements, Annual Book of ASTM Standards. Philadelphia, PA: American Society for Testing and Materials; 1994.

14. Choi YS, Kim JG. Aqueous corrosion behavior of weathering steel and carbon steel in acid-chloride environments. Corrosion 2000;56:1202-1210.

15. Tsai $\mathrm{CH}$, Mansfeld F. Determination of coating deterioration with EIS, Part 2: Development of a method for field testing of protective coatings. Corrosion 1993;49:726-737.

16. Rudenja S, Leygraf C, Pan J, Kulu P, Talimets E, Miki V. Surf Coat Technol 1999;114:129-136. 